\title{
Annular pancreas: many a times incidental finding in CECT abdomen: case report
}

\begin{abstract}
Annular pancreas is developmental morphological variation where the organ surrounds the second part of the duodenum. This may or may not be symptomatic. Duodenal obstruction is the most commonest feature of the entity. Imaging studies are of great importance while establishing the diagnosis. Radiologists are the first to come across this entity while carrying out and studying the contrast enhanced computerizes tomography (CECT) and magnetic resonance imaging (MRI). We present 55 years old male who reported for the dyspepsia and vague pain abdomen of two years duration without any relief with symptomatic treatment. Patient underwent CECT abdomen and was diagnosed as having complete annular pancreas.
\end{abstract}

Keywords: annular pancreas, duodenal obstruction, cect, mri

\author{
Special Issue - 2018
}

\section{Sharma BB, Sakshi Dewan, Naveen Bhardwaj, Mir Rizwan Aziz}

Department of Radio diagnosis, SGT Medical College Budhera, India

Correspondence: Sharma BB, Department of Radio diagnosis, SGT Medical College Budhera (Gurgaon) I22505, C 35 First Floor, Anand Niketan, New Delhi - I I002I, India, Tel 98I8I III3557, Fax +9। II 24II3557,

Email bbhushan986@gmail.com

Received: April 26, 2017 | Published: September 19, 2018
Abbreviations: CECT, computerizes tomography; MRI, magnetic resonance imaging; IPMN, intraductal papillary mucinous neoplasms; ERCP, endoscopic retrograde cholangiopancreatography; MRCP, magnetic resonance cholangiopancreatography

\section{Introduction}

Annular pancreas is a morphological feature which may not present with any symptoms and may remain unnoticed or undiagnosed. It was quoted first time by Tiedemann in 1818. The incidence had been noticed in cadaveric case where it was 5 to 15 per 100.000 adult cases. ${ }^{1}$ The entity causes $1 \%$ intestinal obstruction among children. ${ }^{2,3}$

\section{Case report}

55years old reported with the complaints of dyspepsia and vague abdominal pain of the mild intensity of two years duration. There was no history of any trauma, fever or any long medication. There was no history of postprandial fullness or vomiting. He had been taking symptomatic treatment but without any total relief. On examination he was of averagely built farmer without any other deformity, as per the history he was born in the village without any obstetric complication. Systemic examination was normal. Plain topograph (Figure 1) of chest and abdomen was unremarkable.

Ultrasound abdomen was normal. Patient was subjected to CECT abdomen for any other pathology. CECT abdomen had revealed encircling of second part of the duodenum by the head of the pancreas. This was not causing any obstruction (Figure 2) (Figure 3). No treatment was advised as the entity was not causing any symptoms and this was treated as incidental finding.

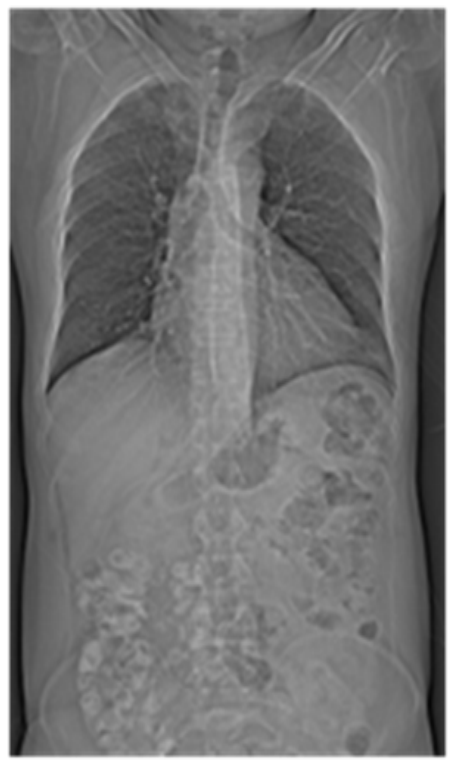

Figure I Plain topographic anteroposterior image. Both the lung fields are normal. There are no signs of intestinal obstruction as the gas shadows depicted are normal. 


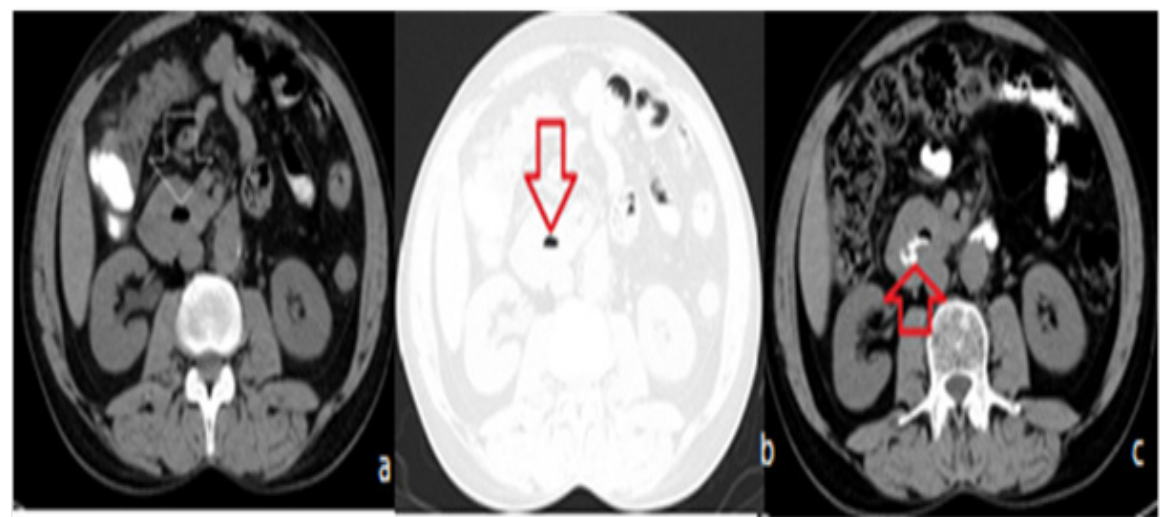

Figure $2 \mathrm{CT}$ abdomen axial sections.

A. Plain with partial oral contrast shows soft tissue density region at the location of the head of pancreas with air in the centre (white thin inverted arrow).

B. Lung window shows the central air more clearly (red arrow).

C. With oral contrast inside the region shown in $2 \mathrm{a}$ image (upward red arrow).
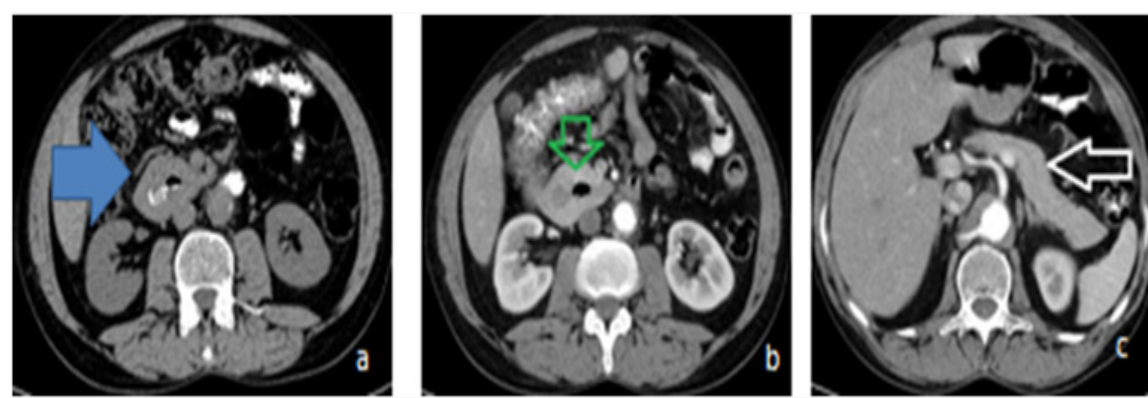

Figure $3 \mathrm{CT}$ axial sections.

A. Before contrast injection the duodenal loop can be seen entrapped in the head of the pancreas (blue arrow).

B. Post contrast section shows well enhancing pancreatic parenchyma with central air lucency (green arrow).

C. Enhancing body and the tail region of the pancreas without any ductal dilatation (white arrow).

\section{Discussion}

Annular pancreas is a rare congenital anomaly and comes to the list of diagnosis when symptomatic. This may present in adulthood also. The anomaly is a result of some deviation of the pathway of the development. This develops as single dorsal and twin ventral buds from the primitive foregut in 5th week of gestation. In normal course both dorsal and fused ventral buds further fuse. Ventral buds form the inferior part of the uncinate process and the inferior part of the head of the pancreas. ${ }^{4}$ In annular pancreas ventral buds do not move with the rotation of the duodenum and result is encircling the descending part of the duodenum. These have been classified as that of two types which are as follow;

\section{i. Complete.}

ii. Incomplete when anterior portion is left uncovered.

Complete is the variety which causes complete obstruction. Incomplete can also become symptomatic due to some inflammation or pathology in it. This predominantly affect males the presentation in children and newborn present with obstruction features. ${ }^{5}$ Adults remain asymptomatic for a long time and invariably may present symptoms during $3 \mathrm{rd}$ and 6 th decades. ${ }^{6} 50 \%$ of these types of cases had been associated with other anomalies ${ }^{7}$ which are as follow: a. Down's syndrome

b. Pancreatic cancer

c. Pancreatitis

d. Pancreas divisum

e. Intraductal papillary mucinous neoplasms (IPMN)

Ultrasound is the first modality by which the newborn or children are subjected for this suspected diagnosis. This is radiation free and shows anatomy in different sections. There is no problem about the motion and regarding repeating the investigation. Adults undergo CECT and MRI abdomen for the diagnosis. Endoscopic Retrograde Cholangiopancreatography (ERCP) can also be carried out to rule out the obstruction and the ductal roadmap. Secretin enhanced Magnetic Resonance Cholangiopancreatography (MRCP) had become more popular as this is non invasive and radiation free. ${ }^{8}$ Both the investigations can elicit the annular duct encircling and joining with the main pancreatic duct. Symptomatic patients may require duodeno duodenostomy or duodeno jejunostomy to bypass the annular pancreas which is the underlying factor for the obstruction. In few cases gastro jujenostomy can also be contemplated. ${ }^{9,10}$ 


\section{Conclusion}

Annular pancreas is a developmental anomaly and the diagnosis is made by the cross section imaging modalities. This may be diagnosed when the patient is symptomatic or asymptomatic. The incidence with symptoms is more found in newborns and children as compared to the adults.

\section{Acknowledgements}

None.

\section{Conflict of interest}

Author declares that there is no conflict of interest.

\section{References}

1. Sandrasegaran K, Patel A, Fogel EL, et al. Annular pancreas in adults. AJR. 2009;193(2):455-460.

2. Norton KI, Tenreiro R, Rabinowitz JG. Sonographic demonstration of annular pancreas and a distal duodenal diaphragm in a newborn. Pediatr Radiol. 1992;22(1):66-67.
3. Moodley S, Hegarty M, Thomson SR. Annular pancreas. S Afr Med J. 2004;94(1):28-30

4. Kozu T, Suda K, Toki F. Pancreatic development and anatomical variation. Gastrointest Endosc Clin N Am. 1995;5(1):1-30.

5. Zyromski NJ, Sandoval JA, Pitt HA, et al. Annular pancreas: dramatic differences between children and adults. J Am Coll Surg. 2008;206(5):1019-1025

6. Chen YC, Yeh CN, Tseng JH. Symptomatic adult annular pancreas. $J$ Clin Gastroenterol. 2003;36(5):446-450.

7. Berrocal T, Torres I, Gutierrez J, et al. Congenital anomalies of the upper gastrointestinal tract. Radiographics. 1999;19(4):855-872.

8. Aksik MF, Sandrasegaran K, Aisen AA, et al. Dynamic secretin enhanced MR cholangiopancreatography. Radiographics. 2006;26(3):665-677.

9. Thomford NR, Knight PR, Pace WG, et al. Annular pancreas in the adult: selection of operation. Ann Surg. 1972;176(2):159-162.

10. Ugrate DA, Dutson EP, Hiyama DT. Annular pancreas in the adult: management with laproscopic gastrojejunostomy. Am Surg. 2006;72(1):71-73. 